\title{
Influence of Various Passivators for Nickel Immobilization in Contaminated Soil of China
}

\author{
Umeed Ali, ${ }^{1}$ Saqib Bashir,, ${ }^{1,2}$ Muhammad Shaaban, ${ }^{3}$ Xiupei Zhou, ${ }^{1}$ Ruili Gao, \\ Jun Zhu, Q, Qingling Fu, and Hongqing $\mathrm{Hu}^{1, *}$ \\ ${ }^{1}$ Key Laboratory of Arable Land Conservation (Middle and Lower Reaches of Yangtse River), Ministry of Agriculture, \\ College of Resources and Environment, Huazhong Agricultural University, Wuhan, China. \\ ${ }^{2}$ Department of Soil and Environmental Science, Ghazi University, Dera Ghazi Khan, Pakistan. \\ ${ }^{3}$ Department of Soil Science, Bahauddin Zakariya University, Multan, Pakistan.
}

Received: March 15, 2019 Accepted in revised form: August 21, 2019

\begin{abstract}
In agricultural field, nickel (Ni) contamination has become a serious concern/threat all over the world due to its hazardous effects on ecosystem and food chain. An incubation study was conducted to investigate the simultaneous efficiency of rice straw (RS) and its derived biochar (BI), calcium carbonate (calcite), zeolite (ZE), and triple superphosphate (TSP) on the stabilization of $\mathrm{Ni}$ in contaminated soil. Various chemical extraction techniques, including the sequential extraction (BCR), leaching toxicity (TCLP) test, and single $\mathrm{CaCl}_{2}$ extraction, were performed. The results revealed that greater reduction in acid-soluble fractions of Ni was observed by $45 \%, 65.1 \%, 42.1 \%, 55.7 \%$, and $33.9 \%$ with RS, BI, ZE, calcite at $2 \%$, and TSP $0.5 \%$ application rate, respectively. Similarly, TCLP and $\mathrm{CaCl}_{2}$-extractable Ni were significantly decreased by $49.8 \%$ and $97.5 \%$ with $2 \% \mathrm{BI}$ application rate, respectively. The soil $\mathrm{pH}, \mathrm{EC}$, and organic matter were significantly improved with the incorporation of RS, BI, ZE, TSP, and calcite amendments. Overall, among all the amendments, the incorporation of $\mathrm{BI}$ and calcite was considered to be the best option for $\mathrm{Ni}$ immobilization and thereby reducing its mobility in Ni contaminated soil. These findings suggest that RS biochar and calcite can be used as Ni stabilizers in contaminated agricultural soils.
\end{abstract}

Keywords: Biochar; Calcite; Ni immobilization; TSP

\section{Introduction}

T HE ACCUMUlation of potential toxic elements (PTEs) in soils has been recognized as one of the major challenges for food security due to their hazardous effects on soil ecosystem (Zhuang et al., 2009; Salam et al., 2018). The PTEs have become more hazardous due to anthropogenic activities such as metallurgy manufacturing, solid waste disposal, mine exploration, paint pigments, and irrigation of untreated water for agricultural production especially in developing countries (Zhao et al., 2014; Shen et al., 2016a). Approximately, 20 million hectares of the total agriculture fields in China have been polluted with PTEs, such as cadmium $(\mathrm{Cd})$, lead $(\mathrm{Pb})$, copper $(\mathrm{Cu})$, nickel $(\mathrm{Ni})$, and zinc (Zn) (Ding et al., 2008; Bashir et al., 2018a). Particularly, Ni contamination in soil has become a global concern due to its high environmental and human health risk (El-Naggar et al., 2018; Li et al., 2018). The accumulation of nickel (Ni) has been reported

*Corresponding author: Key Laboratory of Arable Land Conservation (Middle and Lower Reaches of Yangtse River), Ministry of Agriculture, College of Resources and Environment, Huazhong Agricultural University, Wuhan 430070, China. Phone: +86-15342267201; Fax: +86-27-87282163; E-mail: hqhu@mail.hzau.edu.cn in the soil due to the weathering of rocks (El-Naggar et al., 2018), municipal and industrial wastes, cadmium batteries, and nickel steel and iron alloys (Khan et al., 2017).

Although $\mathrm{Ni}$ is an essential trace element for the proper functioning of plants, its high concentration in soil causes toxic effects on plant growth in polluted soils (Sreekanth et al., 2013; Ramzani et al., 2016). Unfortunately, Ni contamination especially in acidic soil is even more serious because of more susceptibility to $\mathrm{Ni}$ leaching into the ground water relative to alkaline soil (Zhang et al., 2015; El-Naggar et al., 2018). Therefore, the immobilization of Ni contaminated soil has become an important task to reduce its mobility within the soil. For this purpose, various remediation techniques have been performed, including physiochemical approaches and phytoextraction (Shaheen et al., 2015; Bashir et al., 2018a). Recently, the use of several organic and inorganic passivators has attained a considerable attention for the remediation of Ni contaminated soils (Shaheen et al., 2015; Radziemska and Mazur, 2016; Khan et al., 2017).

In China, about $25 \%$ of crop straw has been incorporated into the soil (Shaaban et al., 2018b). Moreover, Rizwan et al. (2016) revealed that the incorporation of rice straw (RS) in contaminated soil not only augmented the immobilized PTEs but also 
improved the soil's health. In the recent decades, Biochar (BI) has attained considerable attention by the researchers due to its availability and ability to detoxify the PTEs. It is prepared from organic biomass through pyrolysis under the limited supply of oxygen (Khan et al., 2017; Shaaban et al., 2018a). BI has exclusive physical and chemical attributes such as high alkalinity, large specific surface area, high cation exchange, porosity, and more functional groups (Shen et al., 2017; Salam et al., 2018), which can play a vital role to immobilize the $\mathrm{Ni}$ in contaminated soils (Shaheen et al., 2015; Shen et al., 2017). In addition to this, BI showed significant potential to improve soil physiochemical properties, immobilize PTEs, and reduce their toxicity to plants when incorporated in contaminated soils (Ramzani et al.,2016; El-Naggar et al., 2018).

Besides this, calcium carbonate (calcite) is an oldest and common chemical passivator that could increase PTE immobilization through adsorption and ion exchange mechanism (Zhai et al., 2018). Consequently, BI (Shaaban et al., 2018a; Zhai et al., 2018) and calcite (Lombi et al., 2003; Mallampati et al., 2012; Huang et al., 2016) are considered as the efficient and common immobilizing agents for acid soil restoration. It has been reported that the incorporation of $\mathrm{BI}$ and calcite to $\mathrm{Ni}$ contaminated soil improves soil health, minimizes the PTE accumulation in plants, and thereby improves their dry biomass (Lee et al., 2009; Cui et al., 2016b; Shahbaz et al., 2018). Furthermore, Huang et al. (2016) reported that calcite can be used to remediate PTEs' polluted soils as it has large surface area porous structure, which may contribute to increase $\mathrm{Ni}$ immobilization in the soil through adsorption and surface complexation (Hung et al., 2016; Lahori et al., 2017).

Similarly, zeolite (ZE) is crystalline inorganic mineral belonging to the aluminosilicate family that exhibits high adsorptive ability for anion and other molecules due to larger specific area (SSA), porous structure, and high cation exchange capacity (CEC) (Bashir et al., 2018c). Up to now, phosphate, especially triple superphosphate (TSP), has been widely applied for the remediation of heavy metals in polluted soils, as well as in water (Huang et al., 2016; Rizwan et al., 2016a). Li et al. (2015) concluded that application of TSP in contaminated soils increased phosphorus and carbon content, which could contribute to heavy metal mobility within soil profile. During the last decade, adequate research has been done for the better understanding of heavy metal immobilization using various types of inorganic and organic passivators in contaminated soils. However, a limited knowledge is available regarding the comparative efficacy of various types of organic and inorganic alkaline materials, that is, RS, RS biochar (BI), TSP, ZE, and calcite for Ni stabilization in acidic contaminated soils. Thus, we hypothesized that the selected organic and inorganic materials will alter soil properties or enhance the sorption/adsorption mechanisms for $\mathrm{Ni}$ in soil and, thus, reduce Ni availability. Therefore, the aim of this study was: (1) to test the relative efficiency of organic and inorganic amendments on $\mathrm{Ni}$ immobilization in contaminated soil and (2) to evaluate the influence of amendments on Ni transformation, leachability, and soil physiochemical properties.

\section{Materials and Methods}

\section{Sampling of soils}

Soil samples, characterized as brown red soil, were collected from surface layer $(0-20 \mathrm{~cm})$ from Jiangxia District,
Wuhan, Hubei, China $\left(30^{\circ} 17.804^{\prime} \mathrm{N}, 114^{\circ} 19.246^{\prime} \mathrm{E}\right)$. These were transferred to the laboratory in polyethylene bags. Soil samples were mixed and dried at room temperature. Samples were crushed manually and passed through $2 \mathrm{~mm}$ sieve.

\section{Soil characterization and amendments}

RSs were obtained from a cropland area of Huazhong Agricultural University, Wuhan, Hubei, China. These were washed with tap water, rinsed with distilled water, and air-dried. The airdried straws were chopped $(1 \mathrm{~mm})$, and chopped samples were placed in ceramic crucibles covered with a close-fitting lid in the absence of oxygen. $\mathrm{RS}$ biochar was produced at $500^{\circ} \mathrm{C}$ pyrolysis temperature in controlled muffle furnace (TDW-2001 1300) for 2 h (Lu et al., 2014; Bashir et al., 2018b). TSP, ZE, and calcite were of pro-analytical grade. Total concentration of $\mathrm{Ni}$ was determined in all amendments by standard Aqua Regia $(\mathrm{HCl}-$ $\left.\mathrm{HNO}_{3}-\mathrm{HClO}_{4}\right)$ digestion method and analyzed using atomic absorption spectrophotometer (AAS) model: Agilent AA240FS. The $\mathrm{pH}$ and $\mathrm{EC}$ of all amendments were also tested.

Experimental design and treatments. In incubation study $200 \mathrm{~g}$ of air-dried sieved $(<2 \mathrm{~mm})$ soil was placed in each plastic cup. Soil was spiked with $\mathrm{Ni}\left(\mathrm{SO}_{4} 6 \mathrm{H}_{2} \mathrm{O}\right)$ salt to obtain $100 \mathrm{mg}$ $\mathrm{Ni} / \mathrm{kg}$ concentration in soil. Soil was incubated at $70 \%$ waterfilled porespace (WFPS) at $25^{\circ} \mathrm{C} \pm 1^{\circ} \mathrm{C}$ for 60 days. The contaminated soil was thoroughly mixed with RS, BI, calcite, and $\mathrm{ZE}$ at the application rate of $1 \%$ and $2 \%$, while TSP was added to soil at the rate of $0.2 \%$ and $0.5 \%$ (w/w) based on previous studies (Huang et al., 2016; Rizwan et al., 2016a; Bashir et al., 2018) and no amendment in the controlled soil. Each treatment had three replicates. The moisture of soil was adjusted to $70 \%$ WFPS after mixing with these passivators in the soil. All plastic cups were covered with a thin plastic lid (containing 80 pin holes) to allow gas exchange and to reduce the moisture loss. Finally, all plastic cups were again incubated at $25^{\circ} \mathrm{C}$ for 65 days. During this incubation period, the moisture content in all cups was maintained at $70 \%$ WFPS using distilled water.

Chemical analyses. Soil $\mathrm{pH}$ and electrical conductivity (EC) were measured with the ratio of soil:water (1:5,1:2.5 v/w) using Mettler Toledo Delta $320 \mathrm{pH}$ meter and DDS-307 EC meter, respectively, according to the method of Bashir et al. (2018d). The organic matter and total nitrogen content of soil were analyzed using $\mathrm{H}_{2} \mathrm{SO}_{4}-\mathrm{K}_{2} \mathrm{Cr}_{2} \mathrm{O}_{7}$ wet oxidation and Kjeldahl method (Lu, 1999). Available phosphorus (P) was extracted using $0.5 \mathrm{~mol} \mathrm{l}^{-1}$ sodium bicarbonate $\left(\mathrm{NaHCO}_{3}\right)$ and then measured by spectrophotometer, while available potassium $(\mathrm{K})$ was extracted with ammonium acetate according to Lu (1999). The particle size of sand, silt, and clay was measured using pipette method (Gee et al., 1986). The CEC was evaluated at $\mathrm{pH} 7.0$ using ammonium acetate method (Hendershot et al., 1993). The elemental composition of all amendments was measured by Micro series Analyzer (EA3000, Italy), and SSA was evaluated with the BET-N 2 method using a surface area analyzer (AUTOSORB-IMP-CR). Total concentration of $\mathrm{Ni}$ in soil was determined by AAS (model: Agilent AA-240FS) followed by standard Aqua Regia $\left(\mathrm{HCl}-\mathrm{HNO}_{3}-\mathrm{HClO}_{4}\right)$ digestion method ( $\left.\mathrm{Lu}, 1999\right)$.

$\mathrm{Ni}$ fractionation and mobility. The sequential extraction technique European Community Bureau of Reference (BCR) 
was adopted to measure the Ni partitioning among different fractions (Rauret et al., 1999), which was described in detail by Bashir et al. (2018a). Briefly, in the first step (acid soluble fraction), the test soil $500 \mathrm{mg}$ was extracted with $20 \mathrm{~mL}$ of $0.11 \mathrm{M} \mathrm{C}_{2} \mathrm{H}_{4} \mathrm{O}_{2}$; after that, the extractants were shaken in a thermostatic reciprocating shaker with $200 \mathrm{rpm}$ at $25^{\circ} \mathrm{C}$. After that the extractants were separated by centrifugation at $4000 \mathrm{rpm}$ for $20 \mathrm{~min}$, and then aliquot was filtered, stored at $4^{\circ} \mathrm{C}$, and concentration of $\mathrm{Ni}$ was determined by AAS. In the second step (easily reducible fraction), remaining soil residues from first step were again extracted with $20 \mathrm{~mL}$ of $0.1 \mathrm{M}$ $\mathrm{NH}_{2} \mathrm{OH}$ in a similar way as described briefly in step 1 . In the oxidizable fraction (step 3 ) remaining soil residues from second step were digested twice in a water bath at $85^{\circ} \mathrm{C}$ with $10 \mathrm{~mL}$ $8.8 \mathrm{M} \mathrm{H}_{2} \mathrm{O}_{2}$, acidified to $\mathrm{pH} 2-3$, and then again extracted with $25 \mathrm{~mL} 1.0 \mathrm{M} \mathrm{NH}_{4} \mathrm{CH}_{3} \mathrm{CO}_{2}$ in a similar way as described briefly in step 1 . In the fourth step (residual fraction), the residual soil from third step was air-dried, grinded, and digested with standard Aqua Regia $\left(\mathrm{HCl}-\mathrm{HNO}_{3}-\mathrm{HClO}_{4}\right)$. After digestion, the samples were diluted to $25 \mathrm{~mL}$ with deionized water, stored at $4^{\circ} \mathrm{C}$, and the concentration of Ni was determined by AAS. Each treatment was performed in triplicate to obtain the mean value.

The leaching toxicity (TCLP) of Ni was analyzed by acetic acid solution ( $\mathrm{pH}$ 2.88) following the procedure of Bashir et al. (2018a). Briefly, TCLP extractable Ni was performed by acetic acid in centrifuge tube by mixing $1.0 \mathrm{~g}$ of air-dried soil with $0.1 \mathrm{M}$ acetic acid extracting solution $(1: 20 \mathrm{w} / \mathrm{v})$, shaken for $18 \mathrm{~h}$, centrifuged, filtered, and measured the Ni concentration by AAS. Similarly, $2.0 \mathrm{~g}$ air-dried soil sample from each treatment was extracted with $0.001 \mathrm{M} \mathrm{CaCl}_{2}(1: 10 \mathrm{w} / \mathrm{v})$ followed by Houben et al. (2013b). The available Ni concentration in soil was determined by AAS model: Agilent AA-240FS. Blanks and the certified reference material (GBW07405) Geophysical Geochemical Exploration, Geological Sciences Institute, Chinese Academy of Sciences, IGGE, Hubei, China were used in all analyses for quality control.

\section{Statistical analysis}

Since the data were normally distributed (Shapiro-Wilk test, $p<0.05$ ), the significance of differences between treatments was checked by one-way ANOVA, using Tukey's test $(p<0.05)$ for post hoc comparisons. Results are expressed as mean \pm standard error.

\section{Results and Discussion}

\section{Physicochemical properties of soil and amendments}

The basic physicochemical properties of soil, organic, and inorganic passivators are given in Tables 1 and 2 . The results revealed that soil texture was classified as silty clay loam with acidic nature $(\mathrm{pH} 5.3 \pm 0.02)$ and low organic matter $(14.79 \pm 0.43 \mathrm{~g} / \mathrm{kg})$. Moreover, all the passivators were alkaline except TSP, which was highly acidic (pH $2.5 \pm 0.003)$. In addition, BI had highest $\mathrm{C}$ content $(47.07 \%)$ followed by RS $36.40 \%$ and calcite $12.12 \%$ (Tables 1 and 2).

\section{Influence of amendments on chemical characteristics of soil}

The results of soil $\mathrm{pH}$ and EC are presented in Figures 1 and 2. The incubation study confirmed that the applications of organic and inorganic passivators, such as BI, calcite, RS,
Table 1. Selected Characteristics of the Soil

\begin{tabular}{lc}
\hline Parameter & Soil \\
\hline pH & 5.3 \\
EC $(\mathrm{mS} / \mathrm{cm})$ & 0.2 \\
Texture & Silty clay loam \\
Sand \% & 12.46 \\
Silt \% & 50.72 \\
Clay \% & 36.82 \\
Organic matter $(\mathrm{g} / \mathrm{kg})$ & 14.79 \\
CEC $(\mathrm{cmole} / \mathrm{kg})$ & 12.75 \\
Total Ni (mg/kg) & 35 \\
Total Nitrogen $(\mathrm{mg} / \mathrm{kg})$ & 1.25 \\
Available Phosphorus $(\mathrm{mg} / \mathrm{kg})$ & 8.74 \\
Available Potassium $(\mathrm{mg} / \mathrm{kg})$ & 150 \\
\hline
\end{tabular}

ZE, and TSP, significantly $(p<0.05)$ improved the chemical properties of Ni contaminated soils. The application of various passivators in polluted soil showed the significant increase in soil pH and EC as illustrated in Figures 1 and 2. The addition of calcite at $1 \%$ and $2 \%$ to $\mathrm{Ni}$ contaminated soil showed the highest increases in soil $\mathrm{pH}$ values $(7 \pm 0.05-$ $7.7 \pm 0.004)$ compared to all amendments and control. Our results were consistent with the observation of Houben et al. (2013a) who showed that the addition of liming agent like calcite logically increased the soil $\mathrm{pH}$ due to its alkaline nature and contained the sufficient amount of $\mathrm{Ca}^{2+}$, which increased alkaline condition in contaminated soils. Similarly, the addition of BI showed the prominent increment in soil $\mathrm{pH}$ compared to control (Fig. 1). The similar trend was also observed by the previous study (Uchimiya et al., 2010). We assumed that an increment in soil $\mathrm{pH}$ could attribute to the alkaline nature, more functional groups, more carbonates, and ash content of BI (Yuan et al., 2011). BI could promote heavy metal immobilization through the adsorption and precipitation (Zhang et al., 2013). Generally, in all amendments, values of soil $\mathrm{pH}$ after 65 days of incubation period increased in the order of calcite $2 \%>$ calcite $1 \%>$ BI $2 \%>$ BI $1 \%>$ RS $2 \%>$ RS $1 \%>$ TSP $0.2 \%>$ TSP $0.5 \%>$ ZE $2 \%>$ ZE $1 \%>$ CK.

Similarly, the EC of soil EC was also influenced when BI, calcite, RS, ZE, and TSP were applied at the rate of $1 \%$ and $2 \%$ (Fig. 2). Compared to the CK, the incorporation of TSP, BI, and calcite at 0.5 and $2 \%$ showed the highest increase in soil EC values $\left(235 \pm 3.77,230 \pm 3.86\right.$, and 194.1 $\left.\pm 4.39 \mu \mathrm{S} . \mathrm{cm}^{-1}\right)$. This trend was similar with the study of Rizwan et al. (2016b).

Table 2. Organic and InORganic Passivator Physiochemical Characteristics

\begin{tabular}{lccccc}
\hline Parameter & $\begin{array}{c}\text { Rice } \\
\text { straw }\end{array}$ & Biochar & Calcite & Zeolite & TSP \\
\hline $\mathrm{pH}$ & 6.8 & 10.29 & 8.6 & 8.2 & 2.5 \\
EC $(\mathrm{mS} / \mathrm{cm})$ & - & 1.1 & 0.1 & 1.1 & 0.001 \\
Total Ni (mg/kg) & 1.5 & 10.75 & 0.75 & 1.5 & $\mathrm{~N} / \mathrm{D}$ \\
BET-SA (m $/ \mathrm{g})$ & 2.3 & 14.5 & 1.77 & 17.13 & 3.66 \\
$\mathrm{C} \%$ & 36.4 & 47.07 & 12.12 & - & - \\
$\mathrm{N} \%$ & 1.99 & 2.53 & 0.102 & 0.026 & 0.011 \\
$\mathrm{O} \%$ & 40.19 & 17.5 & 32.7 & 10.08 & 26.83 \\
$\mathrm{H} \%$ & 5.86 & 1.96 & - & 0.295 & 1.83 \\
Ash \% & - & 65.3 & - & - & - \\
Yield \% & - & 33 & - & - & - \\
\hline
\end{tabular}




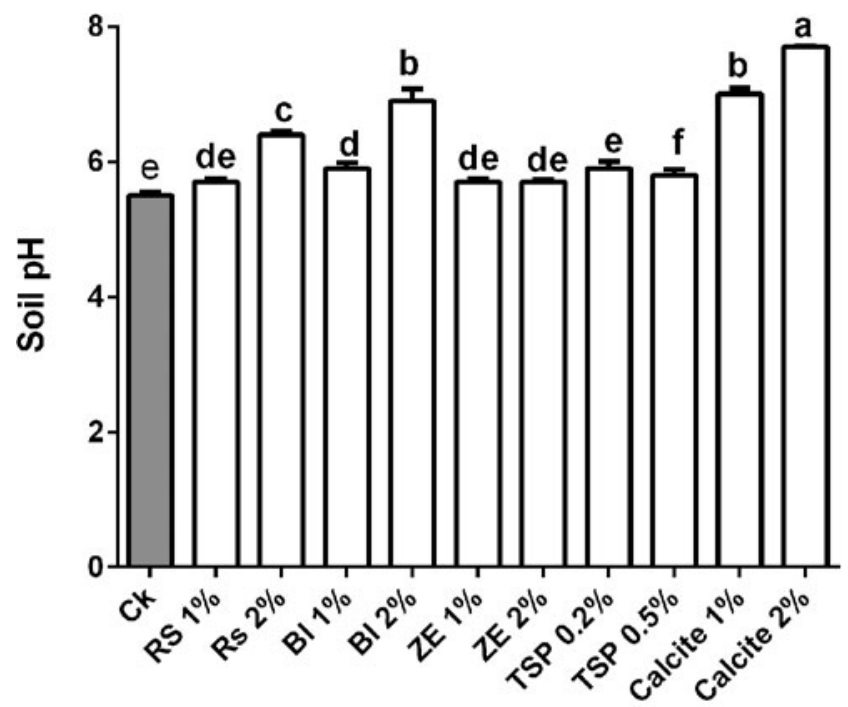

Treatment

FIG. 1. Effects of amendments (rice straw, biochar, zeolite, triple superphosphate, and calcite) on soil $\mathrm{pH}$. Treatments: control (CK), rice straw (RS), biochar (BI), zeolite (ZE), triple superphosphate (TSP), and calcite.

However, $2 \%$ of RS and ZE showed slight increase in soil EC values $(104 \pm 1.64$ and $86.6 \pm 0.74 \mu \mathrm{S} / \mathrm{cm})$ compared to $\mathrm{CK}$. Overall, in all amendments, the values of soil EC after 65 days of incubation period increased in the order of TSP $0.5 \%>\mathrm{BI}$ $2 \%>$ calcite $2 \%>$ calcite $1 \%>$ TSP $0.2 \%>$ BI $1 \%>$ RS $2 \%>$ RS $1 \%>$ ZE $2 \%>$ ZE $1 \%>$ CK.

Similarly, the soil organic matter (SOM) of the brown red soil was increased from $37-68.5 \%, 16-50 \%$ to $10-14 \%$, when soil was amended with BI, RS, and calcite at $1 \%$ and $2 \%$, respectively, relative to the CK (Fig. 3). Our findings are

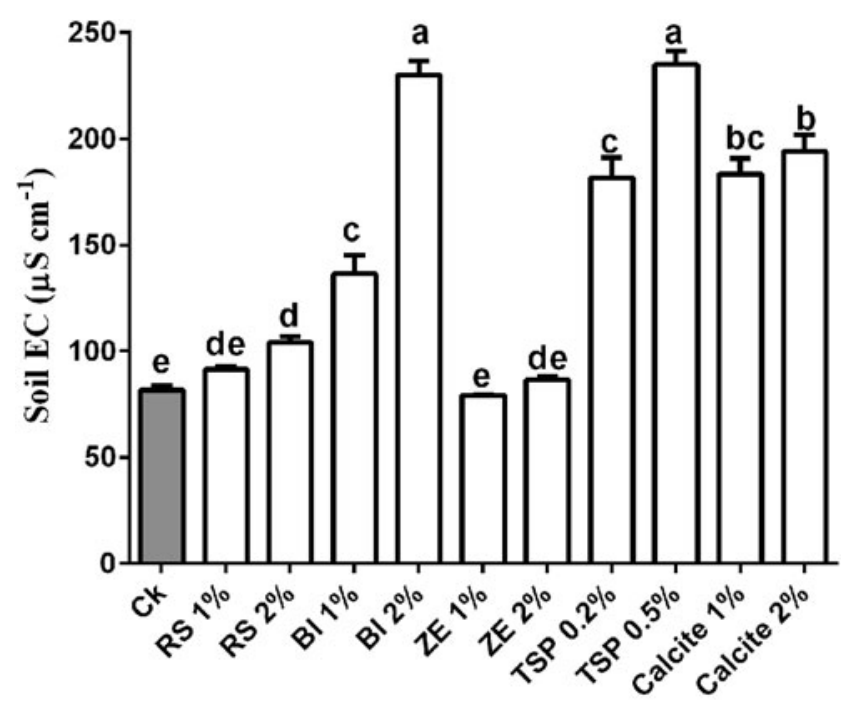

Treatment

FIG. 2. Effects of amendments (rice straw, biochar, zeolite, triple superphosphate, and calcite) on soil electrical conductivity (EC). Treatments: control (CK), rice straw (RS), biochar (BI), zeolite (ZE), triple superphosphate (TSP), and calcite.

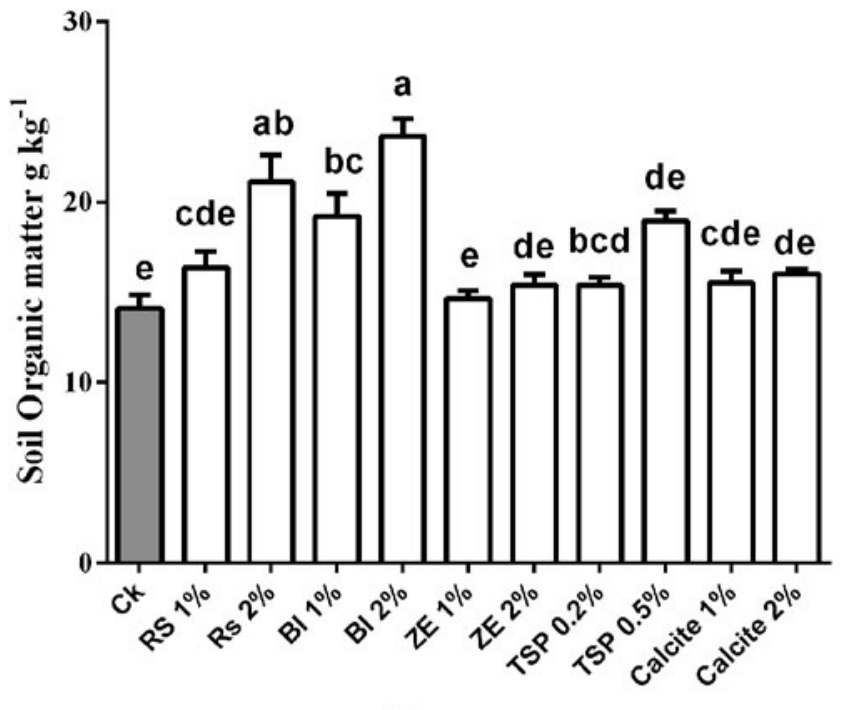

Treatment

FIG. 3. Effects of amendments (rice straw, biochar, zeolite, triple superphosphate, and calcite) on soil organic matter (SOM). Treatments: control (CK), rice straw (RS), biochar (BI), zeolite (ZE), triple superphosphate (TSP), and calcite.

in accordance with the study of Shaaban et al. (2018b) who investigated that the increase in SOM was due to the greater level of $\mathrm{C}$ content in the applied organic and inorganic passivators such as BI, RS, and calcite. Similarly, Bashir et al. (2018b) also concluded that the addition of BI into acidic contaminated soil increased SOM content, which prominently increased the habitat for soil organisms.

\section{Fractionation of $\mathrm{Ni}$}

The concentrations of $\mathrm{Ni}$ in different soil fractions are illustrated in Fig. 4. The acid soluble proportion of Ni was decreased with the increasing rates of various soil amendments. The addition of calcite at $1 \%$ and $2 \%$ showed the significant reduction in acid soluble portion of Ni by 51.2 $55.7 \%$, respectively, relative to CK. Similarly, the greater reduction (54.3-65.1\%) was observed in acid soluble portion of $\mathrm{Ni}$ when $1 \%$ and $2 \% \mathrm{BI}$ was added, respectively, relative to CK (Fig. 4). These findings suggested that the incorporation of $\mathrm{BI}$ and calcite in $\mathrm{Ni}$ contaminated soil was considered as more effective for $\mathrm{Ni}$ immobilization/stabilization during an incubation period. Thus, it can be demonstrated that addition of alkaline materials to acidic soil could ameliorate soil acidity and increase the soil $\mathrm{pH}$, which might contribute to enhance Ni immobilization through adsorption and precipitation. The results suggested that the maximum immobilization of $\mathrm{Ni}$ was occurred due to its transformation from soluble to residual portion. These results are in line with the study of El-Naggar et al. (2018) who suggested that BI was proved to be a suitable candidate to stabilize $\mathrm{Ni}$ and to remediate contaminated soil. The decreases in acid soluble phase of Ni could be due to the larger surface area and higher sorption ability of BI (Shen et al., 2017; Bashir et al., 2018c).

The concentration of $\mathrm{Ni}$ in reducible portion was also increased under the same condition as shown in Fig. 4, particularly, $1 \%$ and $2 \%$ of $\mathrm{BI}$ showed the higher content of $\mathrm{Ni}$ in 
FIG. 4. Effects of amendments (rice straw, biochar, zeolite, triple superphosphate, and calcite) on $\mathrm{Ni}$ fractionation. Treatments: control $(\mathrm{CK})$, rice straw (RS), biochar (BI), zeolite (ZE), triple superphosphate (TSP), and calcite.

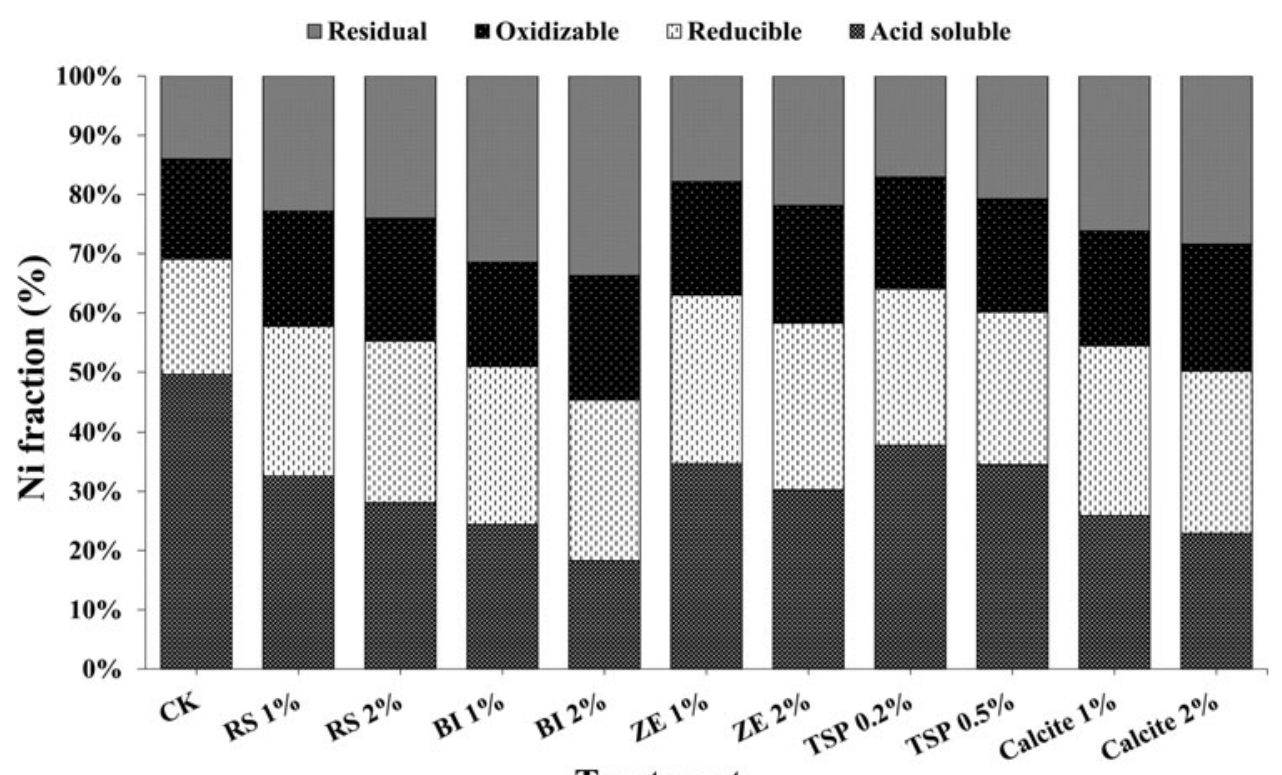

Treatment reducible portion by $26-31.7 \%$, respectively, relative to $\mathrm{CK}$ (Fig. 4). These obtained findings also indicated that the application of calcite, RS, TSP, and ZE increased the reducible portion of $\mathrm{Ni}$. It could be demonstrated that the incorporation of BI showed the formation of Fe-Mn oxides and bonds with the mineral phase of $\mathrm{BI}$, which ultimately resulted in the formation of an insoluble stable complex form of metals (Shaheen et al., 2015).

The oxidizable proportion of $\mathrm{Ni}$ was also significantly increased with the addition of $1 \%$ and $2 \% \mathrm{BI}$ and recorded as $11.5 \%$ and $17 \%$, respectively. The oxidizable portion of $\mathrm{Ni}$ enhanced with the increasing calcite and RS application. Furthermore, the incorporation of other amendments also increased residual portion of Ni. The residual phase of PTEs was strongly bounded with inner sphere in contaminated soil. These results showed that BI had greater impact and more longevity as a passivator in terms of $\mathrm{Ni}$ reduction bioavailability. The BI, calcite, RS, ZE, and TSP at $2 \%$ and $0.5 \%$ application rate increased the residual proportion of $\mathrm{Ni}$ by $129 \%, 95.6 \%, 66.1 \%, 48 \%$, and $41 \%$, respectively, compared to the unamended $(\mathrm{CK})$. In our study, BI was considered more potential amendment for Ni immobilization in soil compared to other passivators in the contaminated soil. According to the results, the acid-soluble phase of $\mathrm{Ni}$ was decreased, while the reducible portion was increased with the increasing rate of BI, calcite, and RS. Obviously, BI has greater surface area, higher $\mathrm{CEC}$, and $\mathrm{pH}$ values, and the functional groups on the surface have the ability to reduce Ni toxicity in contaminated soil, as well as increase the Ni immobilization. These findings are similar with the previous reports (Shen et al., 2016b; Bogusz and Oleszczuk, 2018). It can be demonstrated that $\mathrm{Ni}$ ion can make complexes with functional groups present on BI surface such as carboxylic, phenolic, and hydroxylase compared to the other passivators, which might contribute to enhance the oxidizable and residual portion of $\mathrm{Ni}$ metal in contaminated soil (Rees et al., 2014; Bashir et al., 2018a). The greater immobilization of $\mathrm{Ni}$ by $\mathrm{BI}$ transformed the easily available fraction to geochemically more stable residual portion, thus the availability and activity of $\mathrm{Ni}$ decreased (Jalali and Hemati, 2012; Wu et al., 2013).

\section{$\mathrm{CaCl}_{2}$ and TCLP extractable Ni}

The changes in extractable $\mathrm{Ni}$ by $\mathrm{CaCl}_{2}$ in $\mathrm{Ni}$ contaminated soil amended with various organic and inorganic passivators are illustrated in Fig. 5. All the treatments showed a decreasing trend for soil $\mathrm{CaCl}_{2}$ extractable $\mathrm{Ni}$ after 65 days of incubation period. The $\mathrm{CaCl}_{2}$ extractable $\mathrm{Ni}$ was significantly decreased by $95-97.5 \%$ when treated with $1 \%$ and $2 \%$ of BI, respectively. In contrast, the application of RS and calcite at the rate of $1 \%$ and $2 \%$ significantly decreased the extractable concentration of Ni from 85.5-87.9\% to 95-95.9\% compared to CK (Fig. 5). According to Zeng et al. (2011), soil pH is a key factor to examine the heavy metal fractions and their soluble pools in polluted soils. Our results also showed that the incorporation of BI could decrease the leachability and mobility of $\mathrm{Ni}$ due to the large surface area, high adsorption

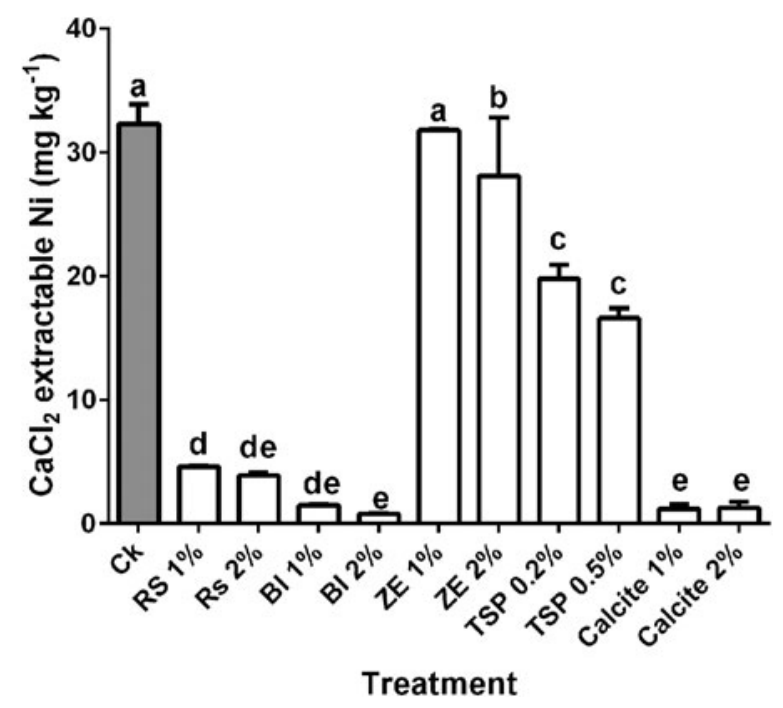

FIG. 5. Effects of amendments (rice straw, biochar, zeolite, triple superphosphate, and calcite) on $\mathrm{CaCl}_{2}$ extractable Ni. Treatments: control (CK), rice straw (RS), biochar (BI), zeolite (ZE), triple superphosphate (TSP), and calcite. 


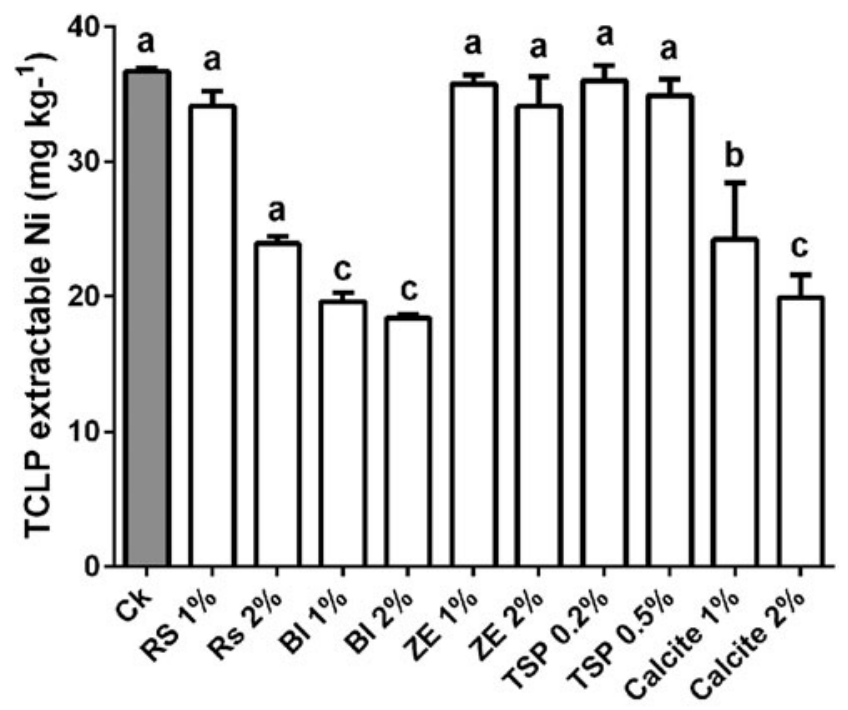

Treatment

FIG. 6. Effects of amendments (rice straw, biochar, zeolite, triple superphosphate, and calcite) on TCLP extractable Ni. Treatments: control (CK), rice straw (RS), biochar (BI), zeolite (ZE), triple superphosphate (TSP), and calcite.

capacity, and precipitation of soluble ions due to the effective increase in soil $\mathrm{pH}$ after these amendments (Shen et al., 2017). The obtained results are similar with the investigation of previous studies (Cui et al., 2016a; El-Naggar et al., 2019). Consequently, BI and calcite had volatile, porous, carbonaceous, and larger pore size and greater surface area, which provided the maximum adsorption capacity. Calcite is an effective option for heavy metal stabilization in polluted soils as Lahori et al., (2017) suggested that calcite have immense tendency to react with heavy metals it can be exhibited by $\mathrm{Ca}^{2+}$ in various frictions in calcite. Similarly, Tahervand and Jalali, (2017) investigated that the mobility of heavy metals was decreased by calcite because of its high $\mathrm{pH}$ and crushed brick and gravel nature. They investigated that calcite decreased $>90 \%$ of PTEs. Similarly, Rizwan et al. (2016a) reported that the application of RS showed the noticeable reduction in the metal concentrations in $\mathrm{CaCl}_{2}$ extract. $\mathrm{BI}$, calcite, and RS had a positive effect on $\mathrm{Ni}$ stabilization in contaminated soil. It can be described that high $\mathrm{pH}$ and calcareous nature of $\mathrm{BI}$ and calcite have ability to minimize $\mathrm{Ni}$ mobility in acidic contaminated soils. Overall, in all amendments, the values of $\mathrm{CaCl}_{2}$ extractable $\mathrm{Ni}$ after 65 days of incubation period reduction were in the order of $\mathrm{BI}>$ calcite $>$ RS $>$ TSP $>$ ZE $>$ CK.

Similarly, according to the obtained findings, the concentration of TCLP extractable Ni was significantly $(p<0.05)$ decreased in organic and inorganic amendments, specifically with the addition of BI and calcite (Fig. 6). The influence of $\mathrm{BI}$ and calcite was considered as more effective for Ni reduction in TCLP extractable Ni. The main mechanism for TCLP Ni reduction in contaminated soil might be due to the greater increase in soil $\mathrm{pH}$, which could promote the metal precipitation in the forms of hydroxides, phosphates, and carbonates, after the incorporation of BI and calcite (Houben et al., 2013a). The BI, calcite, and RS applied at $1 \%$ and $2 \%$ application rate decreased the leachability of $\mathrm{Ni}$ by $46.5-$
$49.8 \%, 34-45.7 \%$, and $7-34 \%$, respectively, compared to CK. These trends are almost similar with the results reported by Lu et al. (2017) that revealed that the application of organic material such as BI decreased the PTEs due to its liming properties, volatile and aromatic substance, and large surface area with high porosity and high CEC. Moreover, the obtained findings also confirmed that the addition of RS exhibited less reduction in TCLP extractable Ni. Furthermore, the application of calcite also showed the reduction in TCLP extractable $\mathrm{Ni}$, at the rate of $2 \%$ by $45.7 \%$. Overall, in all amendments, the values of TCLP extractable Ni after 65 days of incubation period reduction were in the order of $\mathrm{BI}>$ calcite $>$ RS $>$ TSP $>$ ZE $>$ CK.

\section{Conclusions}

The incorporation of RS, BI, and calcite could be proficient to alleviate $\mathrm{Ni}$ toxicity through reducing the bioavailable $\mathrm{Ni}$ concentration $\left(\mathrm{CaCl}_{2}\right.$ extractable $)$ and leaching (TCLP) in soil. Overall, BI applied at the rate of $2 \%$ recognized the most effective organic passivators as a soil amendment for Ni stabilization in contaminated soil. The immobilization of $\mathrm{Ni}$ in soil could be due to the large surface area, alkalinity, and greater CEC of RS derived biochar, while calcite was observed to be effective due to its high $\mathrm{pH}$, which ameliorates soil acidity and $\mathrm{Ni}$ mobility in polluted soil. In addition, the stabilization/immobilization of potential toxic heavy metal especially Ni contaminated soil by these passivators need to be assessed on field conditions. It is suggested that further studies should be conducted to elucidate the effect of various passivators on Ni immobilization under field conditions.

\section{Author Disclosure Statement}

No competing financial interests exist.

\section{Funding Information}

This work was financially supported by the National SciTech Support Plan of China (2015BAD05B02).

\section{References}

Bashir, S., Hussain, Q., Shaaban, M., and Hu, H. (2018a). Efficiency and surface characterization of different plant derived biochar for cadmium (Cd) mobility, bioaccessibility and bioavailability to Chinese cabbage in highly contaminated soil. Chemosphere. 211, 632.

Bashir, S., Rizwan, MS., Salam, A., Fu, Q., Zhu, J., Shaaban, M., and Hu, H. (2018b). Cadmium immobilization potential of rice straw-derived biochar, zeolite and rock phosphate: Extraction techniques and adsorption mechanism. Bull. Environ. Contam. Toxicol. 100, 727.

Bashir, S., Shaaban, M., Hussain, Q., Mehmood, S., Zhu, J., Fu, Q., Aziz, O., and Hu, H. (2018c). Influence of organic and inorganic passivators on $\mathrm{Cd}$ and $\mathrm{Pb}$ stabilization and microbial biomass in a contaminated paddy soil. J. Soils. Sediments. 18, 2948.

Bashir, S., Shaaban, M., Mehmood, S., Zhu, J., Fu, Q., and Hu, H. (2018d). Efficiency of C3 and C4 plant derived-biochar for $\mathrm{Cd}$ mobility, nutrient cycling and microbial biomass in contaminated soil. Bull. Environ. Contam Toxicol. 100, 834.

Bogusz, A., and Oleszczuk, P. (2018). Sequential extraction of nickel and zinc in sewage sludge- or biochar/sewage sludgeamended. Sci. Total. Environ. 636, 927. 
Cui, H., Fan, Y., Fang, G., Zhang, H., Su, B., and Zhou, J. (2016a). Leachability, availability and bioaccessibility of $\mathrm{Cu}$ and $\mathrm{Cd}$ in a contaminated soil treated with apatite, lime and charcoal: A five-year field experiment. Ecotoxicol. Environ. Saf. 134, 148.

Cui, H., Ma, K., Fan, Y., Peng, X., Mao, J., and Zhou, D. (2016b). Stability and heavy metal distribution of soil aggregates affected by application of apatite, lime, and charcoal. Environ. Sci. Pollut. Res. 23, 10817.

Ding, H., Nan, Z., Liu, X., Li, Y., Wang, S., Qin, S., and Zhao, Z.J. (2008). Characteristics of selected heavy metal pollution in suburb cropland, Jinchang City, Gansu, China. J. AgroEnviron. Sci. 27, 2183.

El-Naggar, A., Raja, paksha, A., Shaheen, S., Rinklebe, J., and Ok, Y.S. (2019). Potential of biochar to immobilize nickel in contaminated soils. In. pp 293-318.

El-Naggar, A., Shaheen, S.M., Ok, Y.S., and Rinklebe, J. (2018). Biochar affects the dissolved and colloidal concentrations of $\mathrm{Cd}, \mathrm{Cu}, \mathrm{Ni}$, and $\mathrm{Zn}$ and their phytoavailability and potential mobility in a mining soil under dynamic redoxconditions. Sci. Total Environ. 624, 1059.

Gee, G.W., and Bauder, J.W. (1986). Particle-size analysis. InA. Klute, Ed., Methods of Soil Analysis, Part 1. Physical and Mineralogical Methods, Agronomy Monograph No. 9, $2^{\text {nd }}$ Edition. Madison, WI: American Society of Agronomy/ SoilScience Society of America, p. 383.

Houben, D., Evrard, L., and Sonnet, P. (2013a). Beneficial effects of biochar application to contaminated soils on the bioavailability of $\mathrm{Cd}, \mathrm{Pb}$ and $\mathrm{Zn}$ and the biomass production of rapeseed (Brassica napus L.) Biomass Bioenergy. 57, 196.

Houben, D., Evrard, L., and Sonnet, P. (2013b). Mobility, bioavailability and $\mathrm{pH}$-dependent leaching of cadmium, zinc and lead in a contaminated soil amended with biochar. Chemosphere. 92, 1450.

Huang, G., Su, X., Rizwan, M.S., Zhu, Y., and Hu, H. (2016). Chemical immobilization of $\mathrm{Pb}, \mathrm{Cu}$, and $\mathrm{Cd}$ by phosphate materials and calcium carbonate in contaminated soils. Environ. Sci. Pollut. Res. Int. 23,16856.

Jalali, M., and Hemati, N. (2012). Chemical fractionation of seven heavy metals ( $\mathrm{Cd}, \mathrm{Cu}, \mathrm{Fe}, \mathrm{Mn}, \mathrm{Ni}, \mathrm{Pb}$, and $\mathrm{Zn}$ ) in selected paddy soils of Iran. Paddy Water Environ. 11, 299.

Khan, W, D., Ramzani, P.M.A., Anjum, S., Abbas, F., Iqbal, M., Yasar, A., Ihsan, M.Z., Anwar, M.N., Baqar, M., Tauqeer, H.M., Virk, Z.A., and Khan, S.A. (2017). Potential of miscanthus biochar to improve sandy soil health, in situ nickel immobilization in soil and nutritional quality of spinach. Chemosphere. 185, 1144.

Lahori, A., Zhang, Z., Guo, Z., Mahar, A., Li, R., Kumar, A. M., Sial, T.A., Kumbhar, F., Wang, P., Shen, F., Zhao, J., and Huang, H. (2017). Potential use of lime combined with additives on (im)mobilization and phytoavailability of heavy metals from $\mathrm{Pb} / \mathrm{Zn}$ smelter contaminated soils. Ecotoxicol. Environ. Saf. 145, 313.

Lee, S.-H., Lee, J.-S., Choi, Y.J., and Kim, J.-G. (2009). In situ stabilization of cadmium-, lead-, and zinc-contaminated soil using various amendments. Chemosphere. 77, 1075.

Li, J., Li, Z., Wang, F.M., Zou, B., Chen, Y., Zhao, J., Mo, Q.F., Li, Y., Li, X., and Xia, H. (2015). Effects of nitrogen and phosphorus addition on soil microbial community in a secondary tropical forest of China. Biol. Fertil. Soils. 51, 215.

Li, Y., Fang, F., Wu, M., Kuang, Y., and Wu, H. (2018). Heavy metal contamination and health risk assessment in soil-rice system near Xinqiao mine in Tongling city, Anhui province, China. Hum. Ecol. Risk Assess. 24, 743.
Lombi, E., Hamon, R.E., McGrath, S.P., and McLaughlin, M.J. (2003). Lability of $\mathrm{Cd}, \mathrm{Cu}$, and $\mathrm{Zn}$ in polluted soils treated with lime, beringite, and red mud and identification of a nonlabile colloidal fraction of metals using isotopic techniques. Environ. Sci. Technol. 37, 984.

Lu, K., Yang, X., Gielen, G., Bolan, N., Ok, Y.S., Niazi, N.K., Xu, S., Yuan, G., Chen, X., Zhang, X., Liu, D., Song, Z., Liu, X., and Wang, H. (2017). Effect of bamboo and rice straw biochars on the mobility and redistribution of heavy metals $(\mathrm{Cd}, \mathrm{Cu}, \mathrm{Pb}$ and $\mathrm{Zn})$ in contaminated soil. J. Environ. Manage. 186, 285.

Lu, R.K. (1999). Analytical Methods of Soil Agrochemistry. Beijing (Chinese): Chinese Agricultural Science and Technology Publishing House.

Mallampati, S.R., Mitoma, Y., Okuda, T., Sakita, S., and Kakeda, M. (2012). Enhanced heavy metal immobilization in soil by grinding with addition of nanometallic $\mathrm{Ca} / \mathrm{CaO}$ dispersion mixture. Chemosphere. 89, 723.

Radziemska, M., and Mazur, Z. (2016). Content of selected heavy metals in Ni-contaminated soil following the application of halloysite and zeolite. Ecol. Eng. 7, 125.

Ramzani, P.M.A., Iqbal, M., Kausar, S., Ali, S., Rizwan, M., Virk, Z.A. (2016). Effect of different amendments on rice (Oryza sativa L.) growth, yield, nutrient uptake and grain quality in Ni-contaminated soil. Environ. Sci. Pollut. Res. Int. 23,18585 .

Rauret, G., Lopez-Sanchez, J., Sahuquillo, A., Rubio, R., Davidson, C., Ure, A., and Quevauviller, P. (1999). Improvement of the BCR three step sequential extraction procedure prior to the certification of new sediment and soil reference materials. J. Environ. Monitor. 1, 57.

Rees, F., Simonnot, M.O., and Morel, J.L. (2014). Short-term effects of biochar on soil heavy metal mobility are controlled by intra-particle diffusion and soil $\mathrm{pH}$ increase. Eur. J. Soil Sci. 65, 149.

Rizwan, M.S, Imtiaz, M., Huang, G., Chhajro, M.A., Liu, Y., Fu, Q., Zhu, J., Ashraf, M., Zafar, M., Bashir, S., and Hu, H. (2016b). Immobilization of $\mathrm{Pb}$ and $\mathrm{Cu}$ in polluted soil by superphosphate, multi-walled carbon nanotube, rice straw and its derived biochar. Environ. Sci. Pollut. Res. Int. 23, 15532.

Rizwan, M.S., Imtiaz, M., Chhajro, M.A., Huang, G., Fu, Q., Zhu, J., Aziz, O., and Hu, H. (2016a). Influence of pyrolytic and non-pyrolytic rice and castor straws on the immobilization of $\mathrm{Pb}$ and $\mathrm{Cu}$ in contaminated soil. Environ. Technol. 37, 2679.

Salam, A., Bashir, S., Khan, I., Rizwan, M.S., Chhajro, M., Feng, X., Zhu, J., and Hu, H. (2018). Biochars immobilize lead and copper in naturally contaminated soil. Environ. Eng. Sci. 35, 1360.

Shaaban, M., Van Zwieten, L., Bashir, S., Younas, A., Núñez-Delgado, A., Chhajro, M.A., Kubar, K.A., Ali, U., Rana, M.S., Mehmood, M.A., and Hu, R. (2018a). A concise review of biochar application to agricultural soils to improve soil conditions and fight pollution. J. Environ. Manage. 228, 440.

Shaaban, M., Wu, Y., Peng, Q., Wu, L., Van, Zwieten, L., Khalid, M.S., Younas, A., Lin, S., Zhao, J., Bashir, S., Zafarul-hye, M., Abid, M., and Hu, R. (2018b). The interactive effects of dolomite application and straw incorporation on soil N2O emissions. Eur. J. Soil Sci. 69, 502.

Shahbaz, A.K., Lewinska, K., Iqbal, J., Ali, Q., Mahmood, Ur, R., Iqbal, M., Abbas, F., Tauqeer, H.M., and Ramzani, P.M.A. (2018). Improvement in productivity, nutritional quality, and antioxidative defense mechanisms of sunflower (Helianthus annuus L.) and maize (Zea mays L.) in nickel 
contaminated soil amended with different biochar and zeolite ratios. J. Environ. Manage. 218, 256.

Shaheen, S., Rinklebe, J., and Selim, H. (2015). Impact of various amendments on the bioavailability and immobilization of $\mathrm{Ni}$ and $\mathrm{Zn}$ in a contaminated floodplain soil. Int. J. Environ. Sci. Technol. 12, 2765.

Shen, X., Huang, D.Y., Ren, X.F., Zhu, H.H., Wang, S., Xu, C., He, Y.B., Luo, Z.C., Zhu, and Q.H.J. (2016a). Phytoavailability of $\mathrm{Cd}$ and $\mathrm{Pb}$ in crop straw biochar-amended soil is related to the heavy metal content of both biochar and soil. $J$. Environ. Manage. 168, 245.

Shen, Z., Som, A.M., Wang, F., Jin, F., McMillan, O., and AlTabbaa, A. (2016b). Long-term impact of biochar on the immobilisation of nickel (II) and zinc (II) and the revegetation of a contaminated site. Sci. Total. Environ. 542, 771.

Shen, Z., Zhang, Y., McMillan, O., Jin, F., and Al-Tabbaa, A. (2017). Characteristics and mechanisms of nickel adsorption on biochars produced from wheat straw pellets and rice husk. Environ. Sci. Pollut. Res. 24, 12819.

Sreekanth, T.V.M., Nagajyothi, P.C., Lee, K.D., and Prasad, T.V. (2013). Occurrence, physiological responses and toxicity of nickel in plants. Int. J. Environ. Sci. Technol. 10, 1129.

Tahervand, S., and Jalali, M.J. (2017). Sorption and desorption of potentially toxic metals $(\mathrm{Cd}, \mathrm{Cu}, \mathrm{Ni}$ and $\mathrm{Zn})$ by soil amended with bentonite, calcite and zeolite as a function of pH. J. Geochem. Explor. 181, 148.

Uchimiya, M., Lima, I.M., Thomas, K.K., Chang, S., Wartelle, L.H., and Rodgers, J.E. (2010). Immobilization of heavy metal ions (CuII, CdII, NiII, and PbII) by broiler litter-derived biochars in water and soil. J. Agric. Food Chem. 58, 5538.
Wu, W.H., Xie, Z.M., Xu, J.M., Wang, F., Shi, J.C., Zhou, R.B., and Jin, Z.F. (2013). Immobilization of trace metals by phosphates in contaminated soil near lead/zinc mine tailings evaluated by sequential extraction and TCLP. J. Soils Sediments. 13, 1386.

Yuan, J.H., Xu, R.K., and Zhang, H. (2011). The forms of alkalis in the biochar produced from crop residues at different temperatures. Bioresour. Technol. 102, 3488.

Zeng, F., Ali, S., Zhang, H., Ouyang, Y., Qiu, B., Wu, F., and Zhang, G. (2011). The influence of $\mathrm{pH}$ and organic matter content in paddy soil on heavy metal availability and their uptake by rice plants. Environ. Pollut. 159, 84.

Zhai, X., Li, Z., Huang, B., Luo, N., Huang, M., Zhang, Q., and Zeng, G. (2018). Remediation of multiple heavy metalcontaminated soil through the combination of soil washing and in situ immobilization. Sci. Total Environ. 635, 99.

Zhang, X., Li, J., Wei, D., Li, B., and Ma, Y. (2015). Predicting soluble nickel in soils using soil properties and total nickel. PLoS One. 10, 0133920.

Zhang, X., Wang, H., He, L., Lu, K., Sarmah, A., Li, J., Bolan, N.S., Pei, J., and Huang, H. (2013). Using biochar for remediation of soils contaminated with heavy metals and organic pollutants. Environ. Sci. Pollut. Res. Int. 20, 8472.

Zhao, F.J., Ma, Y., Zhu, Y.G., Tang, Z., and McGrath, S.P. (2014). Soil contamination in China: Current status and mitigation strategies. Environ. Sci. Technol. 49, 750.

Zhuang, P., McBride, M.B., Xia, H., Li, N., and Li, Z. (2009). Health risk from heavy metals via consumption of food crops in the vicinity of Dabaoshan mine, South China. Sci. Total Environ. 407, 1551. 